Savahl, S. et al. (2017). Children's subjective well-being: Multi-group analysis among a sample of children from two socio-economic status groups in the Western Cape, South Africa.

Child Indicators Research, 10: 473-488.

http://dx.doi.org/10.1007/s12187-016-9392-0

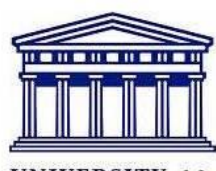

UNIVERSITY of the WESTERN CAPE

\title{
Children's subjective well-being: Multi-group analysis among a sample of children from two socio-economic status groups in the Western Cape, South Africa
}

\author{
Shazly Savahl, Ferran Casas and Sabirah Adams
}

\begin{abstract}
Recent advancements in child well-being research have shown an increased importance of subjective well-being in understanding children and adolescents' quality of life. These advancements have raised questions concerning the extent to which children's subjective perceptions and experiences of well-being can be compared between countries and across diverse cultures. With a dearth of empirical data on cross-cultural comparisons, the validation of existing measures and cross-cultural comparisons have been identified by a number of researchers as critical in contributing to this process, and ultimately to the international dialogue on children's overall quality of life. The aim of the current study was to test two measures of subjective well-being (the Students' Life Satisfaction Scale and the Personal Well-Being Index-School Children) among a sample of children in the Western Cape region of South Africa. Noting the diversity of living experiences between children from different socio-economic status groups in South Africa, the study further aimed to determine the extent to which the measures are comparable across socio-economic status groups. Data from the first wave of the Children's World Survey were used; and included a sample of 100412 year old children randomly selected from 15 schools within the Cape Town Metropole. Located within the goodness of fit theoretical framework, confirmatory factor analysis and structural equation modelling was used to test the overall fit structure; while multi-group factor analysis was used to test measurement invariance across socio-economic status groups. The results show appropriate fit structure for the overall model, with metric and scalar factor invariance tenable across socio-economic status groups. The overall findings suggest that the two measures are appropriate for use with children from low and middle socio-economic status groups in the Western Cape province of South Africa and that the two groups can be compared by correlations, regressions and means.
\end{abstract}

\section{Background}

The children of South Africa have a long history of exposure to political violence, oppression, abuse, and suffering. With the advent of democracy in 1994, the South African government enacted a series of legal commitments to redress childhood adversity and to improve children's well-being and overall quality of life. South Africa's ratification of the United Nations Convention on the Rights of the Child (UNCRC) in 1995 culminated in the 
advancement of further child specific legislation that entrenches the rights and needs of children in the development strategies of the government - guaranteeing children's socioeconomic rights and protection from abuse, exploitation, and neglect (Savahl et al. 2015a).

Through the 20 years of democracy, South Africa has also made significant progress in developing strategies to measure and monitor the state and well-being of children. These initiatives foregrounded the development and collection of objective indicators. Objective indicators often denoted as key national indicators, refer to observable measures that have been developed to measure a range of pre-determined objective standards of well-being. However, over the past few decades, researchers have voiced discontent at the use of objective indicators as the exclusive measure of determining child well-being (Casas et al. 2013a, b, c). This has resulted in the increasing interest in children's subjective well-being.

Subjective well-being is generally defined as a broad concept that includes the cognitive and affective evaluations that individuals make concerning their lives, the events influencing their lives and the circumstances in which they live (Diener 2006, 2005). The cognitive element refers to perceptions of global and domain specific life satisfaction, while the affective element refers to the experience of positive and negative affect. Diener (2009) conceptualises these components as fitting on a hierarchical structure; being moderately correlated, conceptually related, with each making a unique contribution towards subjective well-being. When we ask children about their subjective well-being, we are essentially asking them to appraise the extent to which they are satisfied with their life in general, with various aspects of their life, and how they feel about their life.

When exploring children's well-being in South Africa it is critical to consider the sociohistorical backdrop of Apartheid which characterised the political landscape of South Africa for nearly five decades. The Apartheid regime was founded on the philosophy of institutionalised racism, systematic oppression and domination of one group over another and resulted in the majority of the population being disenfranchised, denied access to resources, land, education opportunities and basic human rights (Savahl et al. 2015b). Amongst the many vestiges of Apartheid on contemporary South Africa is the high levels of social inequality which is evident in the discriminate grouping of locales as 'privileged or high SES' and 'disadvantaged or low SES' (Savahl et al. 2015b). While contemporary literature indicate a definite inverse relationship between inequality and various aspects of well-being (Okulicz-Kozaryn 2015; Ram 2005, 2006), Hall et al. (2012) make the critical point that in South Africa, the burdens of inequality are often endured by children. Similarly, the related constructs of SES, Gross Domestic Product and household income has been shown to have a significant influence on children's subjective well-being (Bradley and Corwyn 2002; Bradshaw, Keung, Rees, \& Goswami, 2011; Bradshaw and Richardson 2009; Rees et al. 2011).

Noting the importance of obtaining children's subjective perceptions of well-being, it has become essential to engage with measures and instruments that can be used to collect data on children's subjective perceptions of well-being. A critical step in this process is to 
ascertain the state of existing measures and to determine the extent to which these measures can be used cross-culturally. Within the international literature, a number of instruments have been identified, which have shown good validity across a range of cultural contexts. Previously the only psychometric scale assessing well-being was the single-item scale the BCantril Ladder ${ }^{\wedge}$ (Casas et al. 2013a, b, c). More recent evidence suggests that the use of multi-item measures of subjective well-being are more stable than single items (Casas et al. 2013a, b, c), reduces the risk of measurement error, and increases the reliability of the measure. Multiple item measures include those that measure global life satisfaction (Students' Life Satisfaction Scale) and those measuring multiple dimensions (Personal Well-Being Index-School Children, the Multidimensional Students' Life Satisfaction Scale and the Brief Multidimensional Students' Life Satisfaction Scale). These measures present with sound structural validity across cultures and groups in developed countries. However, less information is available with regard to its cross-cultural adaptability in developing countries. In a recent study, Casas and Rees (2015) highlight the significance of conducting cross-cultural and international comparative studies on children's subjective well-being. Using data from the International Survey on Children's Well-Being, wherein various subjective well-being measures were used, they found that cross-national comparisons by correlations and regressions were tenable but that means comparisons were not. The authors recommend further international and cross-cultural comparisons which will require validation of subjective well-being measures in diverse contexts. Cross-cultural comparative studies, between Spanish, Chilean and Brazilian adolescents (Casas et al. 2012a, b), between Spanish and Romanian adolescents (Casas et al. 2013a) and between Spanish and Algerian children (Casas et al. 2013c) demonstrate the structural validity and cross-cultural comparability of various subjective well-being instruments across diverse groups. In essence, the studies suggest that these instruments are valid for use with diverse groups (samples) of children, and that the scores can be compared across diverse samples. The instruments are therefore measuring the same construct and the items on the instruments have the same meaning across groups.

The current study hopes to contribute to this growing body of knowledge, by testing the extent to which two measures of subjective child well-being can be used with children in the local Western Cape context in South Africa. Noting the importance of social inequality and the related construct of socio-economic status, the study uses multi-group factor analysis to test the comparability of the measures across a sample of children from low and middle socio-economic status groups. It hopes to add to the database of child specific data and contribute to the international dialogue on children's subjective perceptions of well-being.

\section{Aims of the Study}

The overarching aim of the study was to to determine whether the Personal Well-Being IndexSchool Children and the Students' Life Satisfaction Scale can be used to measure subjective well-being among children in the local context of the Western Cape. More specifically, the study aimed to test the structural validity of these measures and to ascertain whether they can be used across low and middle socio-economic status groups. The following objectives were developed to guide the study: 
1. To test the fit structure of the overall model of the Personal Well-Being Index-School Children and the Students' Life Satisfaction Scale

2. To test the metric and scalar factor invariance of the multi-group model across socioeconomic status groups

3. To test the convergent validity of the Personal Well-Being Index-School Children and the Students' Life Satisfaction Scale

\section{Theory of Model Fit: Goodness of Fit and Fit Indexes}

The study uses Structural Equation Modelling (SEM) and Confirmatory Factor Analysis (CFA) to address the stated aims and objectives. Structural Equation Modelling represents a set of data analysis procedures wherein a Bseries of hypotheses about how the variables in the analysis are generated and related $^{\wedge}(\mathrm{Hu}$ and Bentler $1999, \mathrm{p} .2)$. The essence of SEM is that proposed models (indicating the relationships between variables) are theory driven. Therefore, designation of specified models needs to be based on theoretical relationships between observed and unobserved variables. The key question in SEM is ascertaining the extent to which hypothesised models fit the observed data. Assessment of model fit and the estimation of parameters are the key pursuits of SEM. Within structural equation modelling the most widely used procedures to determine model fit are Model Test Statistics and Approximate Fit Indexes (Hu and Bentler 1999; Kline 2010).

A Model Test Statistic, of which the Chi Square goodness-of-fit statistic is the most popular, determines the degree to which the model covariance matrix significantly differs from the sample covariance matrix. If the difference is not significant, then it may be considered as being due to sampling error. It is for this reason that it is often referred to as a badness-offit test, as lower values indicate a higher degree of correspondence between the specified models and the data (Kline 2010).

Approximate Fit Indexes are defined as continuous measures of model-data correspondence and is not concerned with hypothesis testing (Kline 2010). The two most widely used approximate fit indexes are absolute and incremental fit indexes. Absolute fit indexes assesses how well a hypothesised model fits the sample data in comparison to no baseline model, while incremental fit indexes attempt to fit a hypothesised model to a baseline model wherein the null hypothesis is that the variables in the model are uncorrelated (Hooper et al. 2008; Hu and Bentler 1999). Examples of absolute fit indexes include the root mean square error of approximation (RMSEA) and the standardized root mean square residual (SRMR). Examples of incremental fit indexes include the comparative fit index (CFI), the Tucker-Lewis Index (TLI) and the Normed Fit Index (NFI). It is widely recommend that more than one fit index be used to overcome the limitations of using a single index (Jaccard and Wan 1995). If models present with a good fit, significance of causal paths can be established which would allow for the examination of discrepancies between variables. Following recommendations by Jackson et al. (2009) and Kline (2010), the CFI (absolute fit), and the RMSEA and SRMR (incremental fit), were used to determine model fit in the current study. These recommendations have been used in a range of validation studies on child subjective well- 
being instruments (see e.g. Casas et al. 2012a, b, 2013a, b, c) using cut-scores of $>.950$ accepted for CFI and scores <.05 regarded as a good fit for RMSEA and SRMR. These cut scores are applied in the current study.

\section{Method}

The study follows a cross-sectional survey design and uses data from the first wave (deep pilot) of the Children's World's International Survey on Children's Well-Being (ISCWeB) (see Casas and Rees 2015). The ISCWeB project is an international inter-country study which aims to collect substantive data from children on factors relating to their well-being, satisfaction with various aspects of their life, living conditions, material possessions, time use and experiences of daily life. While the international project targeted three age groups $(8,10,12)$, due to resource constraints the South African study adopted an exploratory design which was limited to the 12-year old cohort.

\subsection{Sampling}

The current study was conducted in the Western Cape Province which is one of the nine provincial regions in South Africa. The Western Cape comprises one metropolitan area, the City of Cape Town, and five district municipalities which encompass combinations of urban, semi-urban, and rural communities. The study participants were drawn from low and middle SES communities located in the City of Cape Town which is characteristically urban with an estimated population of 6.2 million (Statistics South Africa 2015). The sampling frame for the study comprised all 12-year old children attending the 646 primary schools in the four urban Education Management Districts (EMDC's) of the Western Cape Education Department; that is Metro Central, Metro East, Metro North, and Metro South. The sample was randomly selected using a twostage stratified approach- the first strata was the schools' location in relation to the EMDC's, the second strata was SES level, either low or middle. This sampling approach ensured that children from diverse cultural and geographical locations were selected. The sampling process yielded a final sample of eight low SES and seven middle SES schools, with a total of 1048 children participating in the study.

\subsection{Instrumentation}

While the original questionnaires were constructed in English and Spanish by the core research group, the South African study adapted the English version to the current context. The adaptation process entailed three components: cognitive testing, the translation of the questionnaire to Afrikaans, and the subsequent piloting of both the English and Afrikaans adapted versions of the questionnaires. Firstly, the cognitive testing comprised two focus group sessions with 10 children aged 12-years who were purposively chosen from schools included in the sampling frame. This component facilitated the rephrasing, and modifications of the scale items on the questionnaire. Secondly, after cognitive testing, the questionnaire was translated into Afrikaans by two external first-language Afrikaans reviewers employing the backward translation method. Finally, the questionnaires were then piloted with 100 12-year old children who were randomly selected from the low and middle SES schools forming part of the sampling frame. A number of internationally validated scales 
were included in the questionnaire. These included the Students' Life Satisfaction Scale (Huebner 1991), the Personal Well-Being Index-School Children (Cummins and Lau 2005) and the single-item scale on Overall Life Satisfaction (Cummins and Lau 2005). To facilitate comparisons, these scales have been transformed in 100-point scales during data analysis.

\subsection{Students' Life Satisfaction Scale}

The Students' Life Satisfaction Scale (SLSS) is a 7-item measure designed by Huebner (1991) to assess global life satisfaction of children between the ages of 8 and 18. The scale items are domain or context-free, with respondents required to indicate their satisfaction on a 5-point Likert scale ranging from o (Bvery much disagree ${ }^{\wedge}$ ) to 4 (Bvery much agree ${ }^{\wedge}$ ). The scale has shown acceptable internal consistency (Huebner 1991), convergent validity (Casas et al. 2013b; Huebner 1991), criterion validity (Huebner et al., 2003), discriminant validity (Huebner and Alderman 1993), and predictive validity (Suldo and Huebner 2004). A summary of the scale's psychometric properties is provided by Huebner and Hills (2013).

\subsection{Personal Well-Being Index-School Children and Adolescents}

The Personal Well-Being Index-School Children (PWI-SC) was designed by Cummins and Lau (2005) to assess children's subjective well-being across a range of seven life satisfaction domains: standard of living, health, achievement life, relationships, personal safety, community-connectedness and future security. These domains are designed to represent a Bfirst level deconstruction of satisfaction with 'life as a whole'^ (Tomyn and Cummins 2011, p. 408). The scale is often adapted to include items on school experience and religion and spirituality. In the current study, the item on school experience was included as item 8. Response options are presented on an end-labelled 11-point scale, ranging from o (complete dissatisfaction) to 10 (complete satisfaction). The PWI-SC is scored by calculating the composite mean of the domains scores. Cummins (1995) makes reference to a normative range of between 70 and $80 \% \mathrm{SM}$ for western populations and $10 \%$ less for non-western populations. The PWI-SC has shown a satisfactory Alpha coefficient of 0.82 (Tomyn and Cummins 2011).

\subsection{Single Item on Overall Life Satisfaction}

An item assessing Overall Life Satisfaction (OLS) (Cummins and Lau 2005) on an end-labelled o-10 scale was also included using the following wording: BHow satisfied are you with your life as a whole ${ }^{\wedge}$ The importance of including a single item on life satisfaction was identified by Campbell et al. (1976) and further corroborated by Cummins and Lau (2005), Casas et al. (2013a, b, c), and Casas and Rees (2015) who note the use of the OLS as a means to ascertain convergent validity of subjective well-being scales.

\subsection{Procedure and Ethics}

Ethics clearance was obtained from the Senate Research Committee of the university at which the researchers are based as well as the Western Cape Education Department. Thereafter, members of the research team met with the principals and life skills teachers of the selected schools to discuss the details of the project. Within the schools which agreed to participate in the study, an information session was held with all the 12-year old children where the 
researchers presented the particulars of the project, such as the aims of the study, what their involvement would entail, as well as the key ethics principles of informed consent, confidentiality, their right to withdraw, and privacy. The researchers also informed the participants about the dissemination procedure for the findings of the study. The children who agreed to participate in the study were required to provide signed consent, and obtain consent from their parent/guardian. Only the children who returned their signed consent forms participated in the study. The questionnaires were researcher administered in the classroom setting during the administration period at the beginning of the school day. The double entry method was utilised to capture the data, which was carried out by the research team. The principal investigators cleaned the data using a two-step sequential process. In the first step spoilt questionnaires were omitted. These included cases wherein more than $25 \%$ of the variables on a questionnaire were missing. In the second step, following recommendations by Casas et al. (2012a, b), all cases on the measurement scales (SLSS, PWISC) with more than two missing values were deleted, while those with two or less missing values were substituted by regression. This process resulted in 44 (4.2 \%) of the questionnaires being excluded from the original 1048, yielding a final sample of 1004 children. This included $58.60 \%$ from the low SES and $41.40 \%$ from the middle SES group; with a gender composition of $53.9 \%$ (girls) and $46.10 \%$ (boys).

\subsection{Data Analysis}

The Statistical Package for the Social Sciences (version 23) software was used to analyse the data. To test the validity of the measures in the South African context and across diverse SES groups, confirmatory factor analysis (CFA) using AMOS (version 23) was used. Maximum likelihood estimation was used with kurtosis and departures from normality attended to using the bootstrap method (500 samples) as specified in AMOS 23. As previously stated, based on recommendations by Jackson et al. (2009) and Kline (2010), the CFI, RMSEA and SRMR were used as fit indexes. Results higher than .950 were accepted for CFI and results below .05 were regarded as a good fit for RMSEA and SRMR. Improvement of model fit was achieved by excluding items with excessively low factor loadings $(<.2)$ and the addition of error covariance constraints (Kline 2010).

To compare the results between the low and middle SES groups, factor invariance, which refers to the extent that items in the measure have the same meaning between groups, was considered (Meredith 1993). If factor invariance is not met, then group comparisons on the measured variables would have ambiguous and unreliable interpretations (Millsap and Olivera-Aguilar 2012). Factor invariance is generally conceptualised on a hierarchical structure assessed through the application of incrementally restrictive constraints. In the current study factor invariance of multi-group models were tested in three steps. In the first step, configural factor invariance, which assesses an unconstrained multi-group model wherein the parameters are freely estimated, was tested. Thereafter, metric factor invariance, which is a requisite for comparing covariance, correlations or regression coefficients, was tested by constraining the factor loadings of the baseline model. Finally, scalar factor invariance, which is a requisite for comparing means between groups, was tested by 
constraining the factor loadings and intercepts. To test convergent validity a structural equation model was tested by including OLS into the overall model.

\section{Results}

\subsection{Descriptive Statistics}

Skewness of the items ranged from .680 to -.1222 for the SLSS and -.901 to -2.145 for the PWI-SC; with Kurtosis from 1.116 to -.1377 for the SLSS and -.226 to 4.728 for the PWI-SC. Cronbach's Alpha for the SLSS was an acceptable .75 and .68 for the PWI-SC. Table 1 shows the mean composite scores for the three scales used in the study.

\subsection{Confirmatory Factor Analysis}

In order to assess the validity of the factorial structure of the scales, confirmatory factor analysis was used to test the fit statistics of various models (presented in Table 2). Initial models for the SLSS and PWI-SC showed adequate fit (Model 1 and Model 2). However, modified models with three error co-variances (items 1 to item 2; item 3 to item 4; item 6 to item 7) for the SLSS (Model 3); and two co-variances (items 4 to item 5 ; item 7 to item 8) for the PWI-SC (Model 5) produced an adequate fit (see Figs. 1, 2 and 3). Standardised factor loadings for the two scales ranged from 0.19 to 0.81 and are presented in Table 3. Factor loadings for items 3 and 4 presented with low scores of 0.19 and 0.29 respectively. These two negatively phrased items also showed a high correlation (0.44) with one another.

Table 1 Mean composite scores for SLSS, PWI-SC and the OLS on 100-point scale

\begin{tabular}{llll}
\hline & $\mathrm{N}$ & Mean & Std. deviation \\
\hline SLSS composite & 1004 & 65.60 & 18.59 \\
PWI-SC composite & 1004 & 81.90 & 13.60 \\
OLS & 1004 & 85.10 & 24.29 \\
\hline
\end{tabular}


Table 2 Fit indexes for the overall pooled data (Models 1-7) and multi-group data (Models 8-13)

\begin{tabular}{|c|c|c|c|c|c|c|c|}
\hline \multicolumn{2}{|c|}{ Model } & \multirow{2}{*}{$\frac{\chi^{2}}{299.63}$} & \multirow{2}{*}{$\frac{\mathrm{df}}{14}$} & \multirow{2}{*}{$\frac{\mathrm{p} \text {-value }}{0.00}$} & \multirow{2}{*}{$\frac{\text { CFI }}{0.862}$} & \multirow{2}{*}{$\frac{\text { RMSEA }}{0.144(0.129-0.157)}$} & \multirow{2}{*}{$\frac{\text { SRMR }}{0.086}$} \\
\hline 1 & SLSS Initial Model & & & & & & \\
\hline 2 & PWI-SC Initial Model & 124.09 & 20 & 0.00 & 0.890 & $0.072(0.060-0.084)$ & 0.048 \\
\hline 3 & $\begin{array}{l}\text { SLSS Modified Model } \\
\text { with } 3 \text { error co-variances }\end{array}$ & 18.42 & 11 & 0.07 & 0.996 & $0.026(0.000-0.046)$ & 0.020 \\
\hline 4 & $\begin{array}{l}\text { SLSS Modified Model with } \\
2 \text { error co-variances } \\
\text { (excl. item } 3 \& 4)\end{array}$ & 4.12 & 3 & 0.24 & 0.999 & $0.060(0.000-0.058)$ & 0.008 \\
\hline 5 & $\begin{array}{l}\text { PWI-SC Modified Model with } \\
2 \text { error co-variances }\end{array}$ & 53.01 & 18 & 0.00 & 0.963 & $0.044(0.031-0.058)$ & 0.029 \\
\hline 6 & $\begin{array}{l}\text { PWI-SC/SLSS (SEM) Initial } \\
\text { model (excl. item } 3 \text { \& } 4 \text { on SLSS) }\end{array}$ & 258.07 & 64 & 0.00 & 0.936 & $0.055(0.048-0.062)$ & 0.039 \\
\hline 7 & $\begin{array}{l}\text { PWI-SC/SLSS (SEM) Modified model } \\
\text { (excl. item } 3 \text { \& } 4 \text { on SLSS, } \\
\text { with } 8 \text { error co-variances) }\end{array}$ & 94.98 & 56 & 0.00 & 0.987 & $0.026(0.017-0.035)$ & 0.024 \\
\hline 8 & $\begin{array}{l}\text { PWI-SC/SLSS (SEM) (Multi-group) } \\
\text { SES (Unconstrained) }\end{array}$ & 175.40 & 112 & 0.00 & 0.980 & $0.024(0.017-0.030)$ & 0.027 \\
\hline 9 & $\begin{array}{l}\text { PWI-SC/SLSS (SEM) (Multi-group) } \\
\text { SES (Constrained Factor Loadings) }\end{array}$ & 185.50 & 123 & 0.00 & 0.980 & $0.024(0.016-0.029)$ & 0.032 \\
\hline 10 & $\begin{array}{l}\text { PWI-SC/SLSS (SEM) (Multi-group) } \\
\text { SES (Constrained Factor } \\
\text { Loadings \& Intercepts) }\end{array}$ & 229.79 & 134 & 0.00 & 0.970 & $0.027(0.021-0.032)$ & 0.032 \\
\hline 11 & $\begin{array}{l}\text { PWI-SC/SLSS - OLS SEM } \\
\quad \text { (Pooled sample) }\end{array}$ & 119.98 & 67 & 0.00 & 0.984 & $0.028(0.020-0.036)$ & 0.025 \\
\hline 12 & $\begin{array}{l}\text { PWI-SC/SLSS - OLS (SEM) } \\
\quad \text { Multi-group SES (Unconstrained) }\end{array}$ & 213.92 & 134 & 0.00 & 0.977 & $0.024(0.018-0.030)$ & 0.028 \\
\hline 13 & $\begin{array}{l}\text { PWI-SC/SLSS - OLS (SEM) } \\
\text { (Constrained Factor Loadings } \\
\text { \& Intercepts) }\end{array}$ & 267.04 & 156 & 0.00 & 0.968 & $0.027(0.021-0.032)$ & 0.032 \\
\hline
\end{tabular}

When a model (Model 4) was tested without item 3 and 4 , the fit structure improved substantially.

In the next step, an overall model using the two scales, with correlated latent variables was tested. Whilst the initial model (Model 6 in Table 2) presented with an adequate fit, a modified model (Model 7 in Table 2) with eight error co-variances presented with an improved fit.

As previously indicated, to compare coefficients across SES groups, factor invariance was tested using three steps wherein restrictive constraints were incrementally applied. To compare coefficients across SES groups, metric factor invariance needs to be tenable. Factor 
invariance refers to the extent to which scale items are understood to have the same meaning for members of different groups and is a mandatory condition for group comparison.

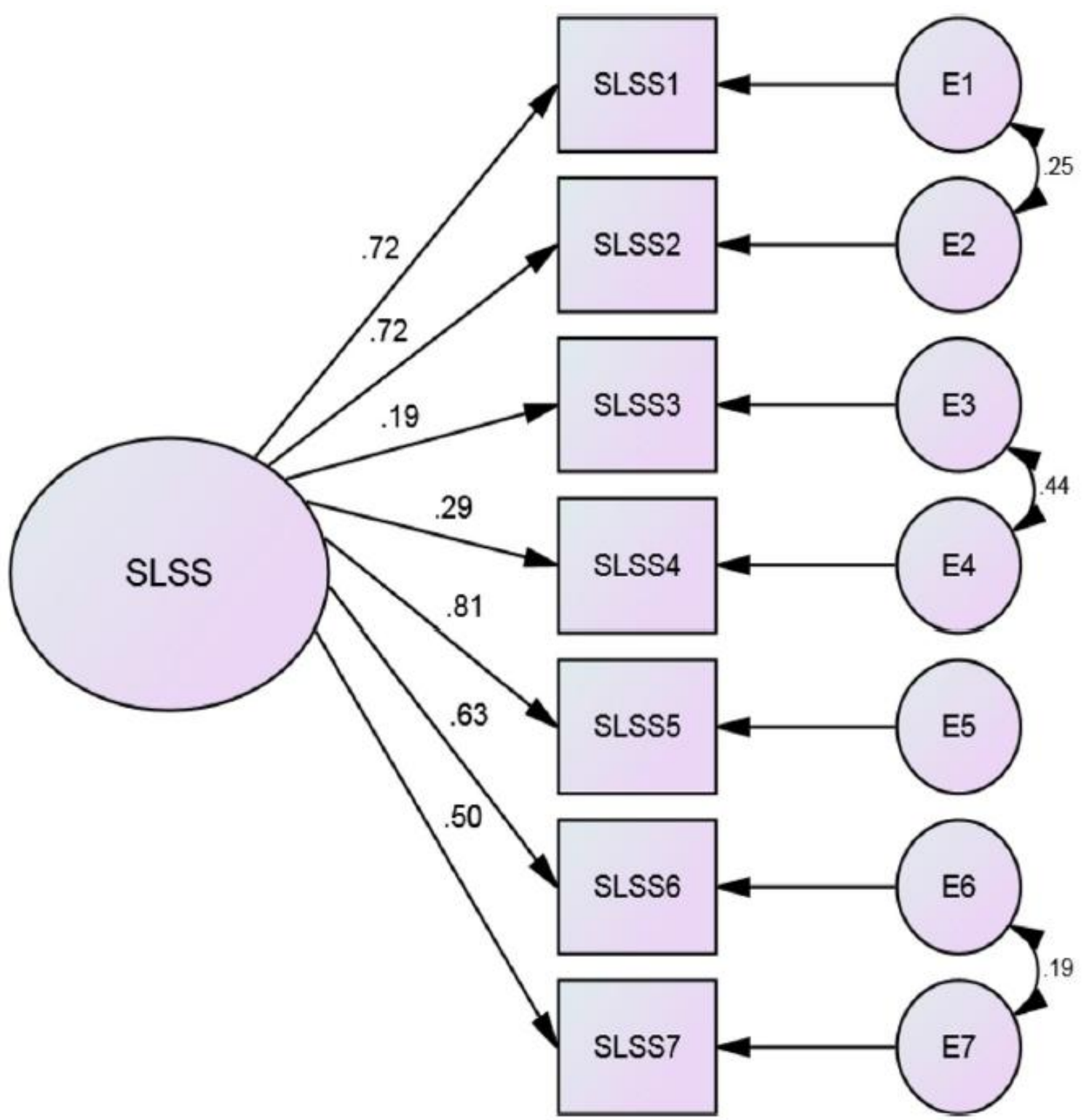

Fig. 1 SLSS (Modified Model with 3 error co-variances) using the pooled data

If this is not met, then group differences in means or regression coefficients can be accounted for by true differences in group distributions or to a different understanding of the items (Casas et al. 2012a, b). The first step when testing factor invariance is to fit an unconstrained multi-group model (configural invariance). If this baseline model shows adequate fit, then constrained factor loadings needs to be tested. If the constrained model does not show a significantly worse fit (increases by more than 0.01) than the unconstrained, then metric factor variance is tenable (Cheung and Rensvold 2002). Findings from the current study show adequate fit statistics for the unconstrained multi-group model (Model 8 in Table 2) as well as the model with constrained factor loadings (Model 9 in Table 2). This means that 
metric factor invariance is tenable and that groups can be compared by regressions and correlations.

The next model (Model 10 in Table 2) tested scalar factor invariance which assesses the extent to which groups can be compared across means. Scalar factor invariance is tested by constraining the factor loadings and intercepts and is tenable if the fit statistics of the model is not significantly worse (increases by more than 0.01) than the subsequent model (Cheung and Rensvold 2002). In the current study scalar factor invariance was tenable; this means that the overall model can be compared across regressions, correlations and means.

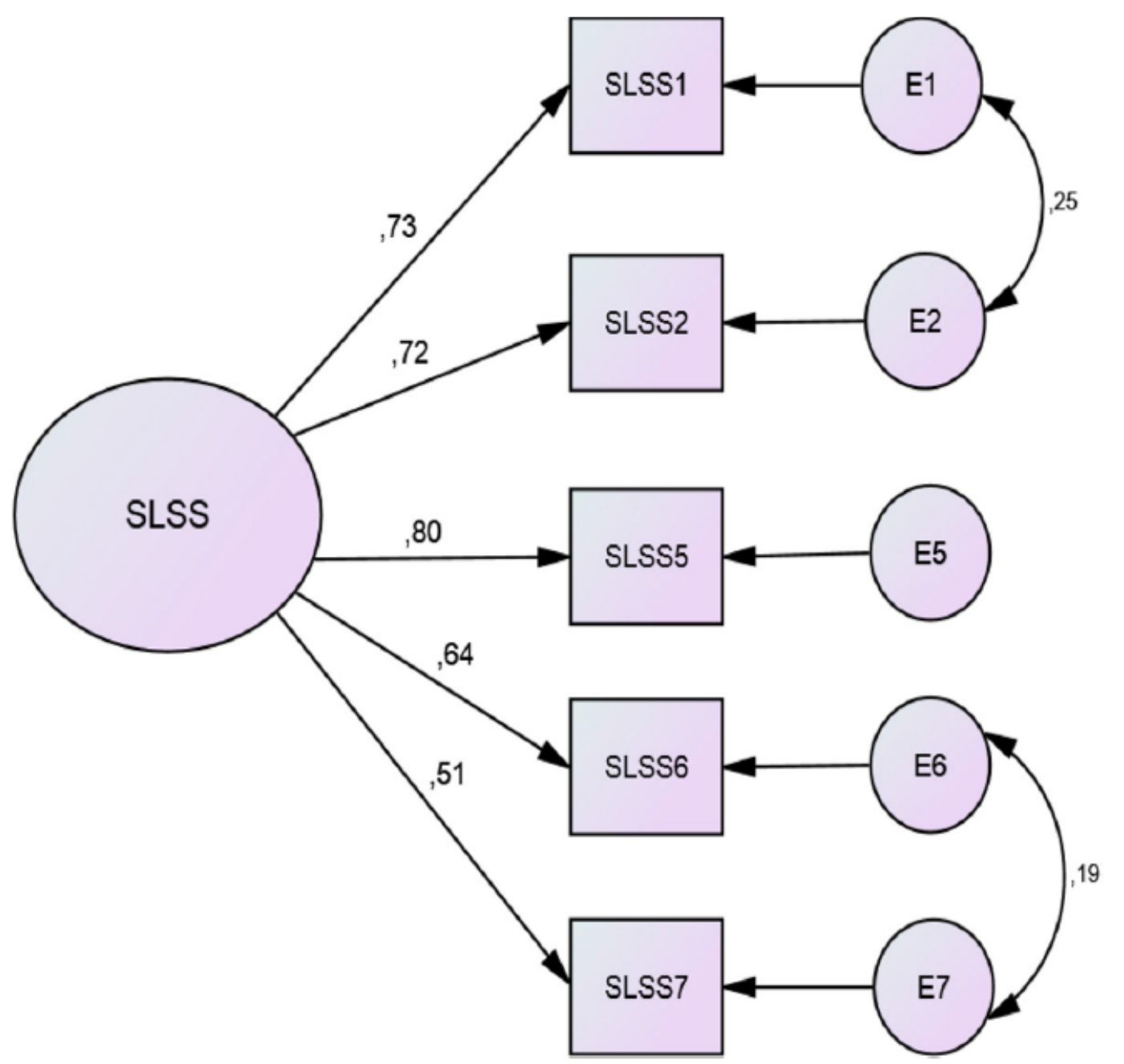

Fig. 2 SLSS (Modified Model with 2 error co-variances: excluding item $3 \&$ 4) using the pooled data

In Model 11 (Table 2), the observed variable OLS, was included in the model with the two latent variables (SLSS \& PWI-SC). Figure 4 shows the standardised estimates of the overall model (including OLS) and Table 4 the SES specific standardised regression weights (with constrained loadings and intercepts). Standardised estimates show adequate loadings for all items across SES groups. The standardised regression weights also show adequate loadings of the latent variables onto OLS. 
Standardised regression weights for the SLSS to the OLS were 0.493 for both the low and the middle SES group. For the PWI-SC the standardised regression weights to the OLS was 0.465 for the low SES group and 0.527 for the middle SES. Furthermore, for the low SES group, standardized regression weights for the individual items of the SEM model ranged from 0.290 for item 7 (Satisfied with things I do away from home) on the PWI-SC to 0.801 on item 5 (I have a good life) on the SLSS. Standardised regression weights for the middle SES group ranged from 0.441 for item 7 on the PWI-SC to 0.751 for item 5 on the SLSS. No significant mean differences were found between low and middle SES groups for both the SLSS and the PWI-SC.

\section{Discussion}

While children in South Africa face a range of adverse conditions that negatively impacts on their daily life experiences and overall well-being, it is critical to note that the composite scores for the three scales show a general trend towards high levels of subjective well-being. It is therefore, essential to ascertain the validity of these scales within the South African context. With regard to the fit structure of the scales, some interesting findings were forthcoming. The findings of the current study confirm appropriate fit structure for both the SLSS and PWI-SC. The SLSS presented with an excellent fit structure with 2 error co-variances and with item 3 (I wish I had a different life) and item 4 (I would like to change many things in my life) removed. Given the low factor loadings of these items, especially in relation to the other items on the scale, it is recommended that they be flagged when conducting further research with child populations in the Western Cape. Research conducted by Casas and Rees (2015) found similar discrepancies with these items of the SLSS.

Considering the high level of social inequality in South Africa, the experience of children and childhood in South Africa is characterised by opportunity and resources for some and deprivation and impoverishment for others (Savahl et al. 2015b). Considering this context, a multi-group SES model testing how different SES groups responded to the various items on the SLSS and PWI was conducted. 


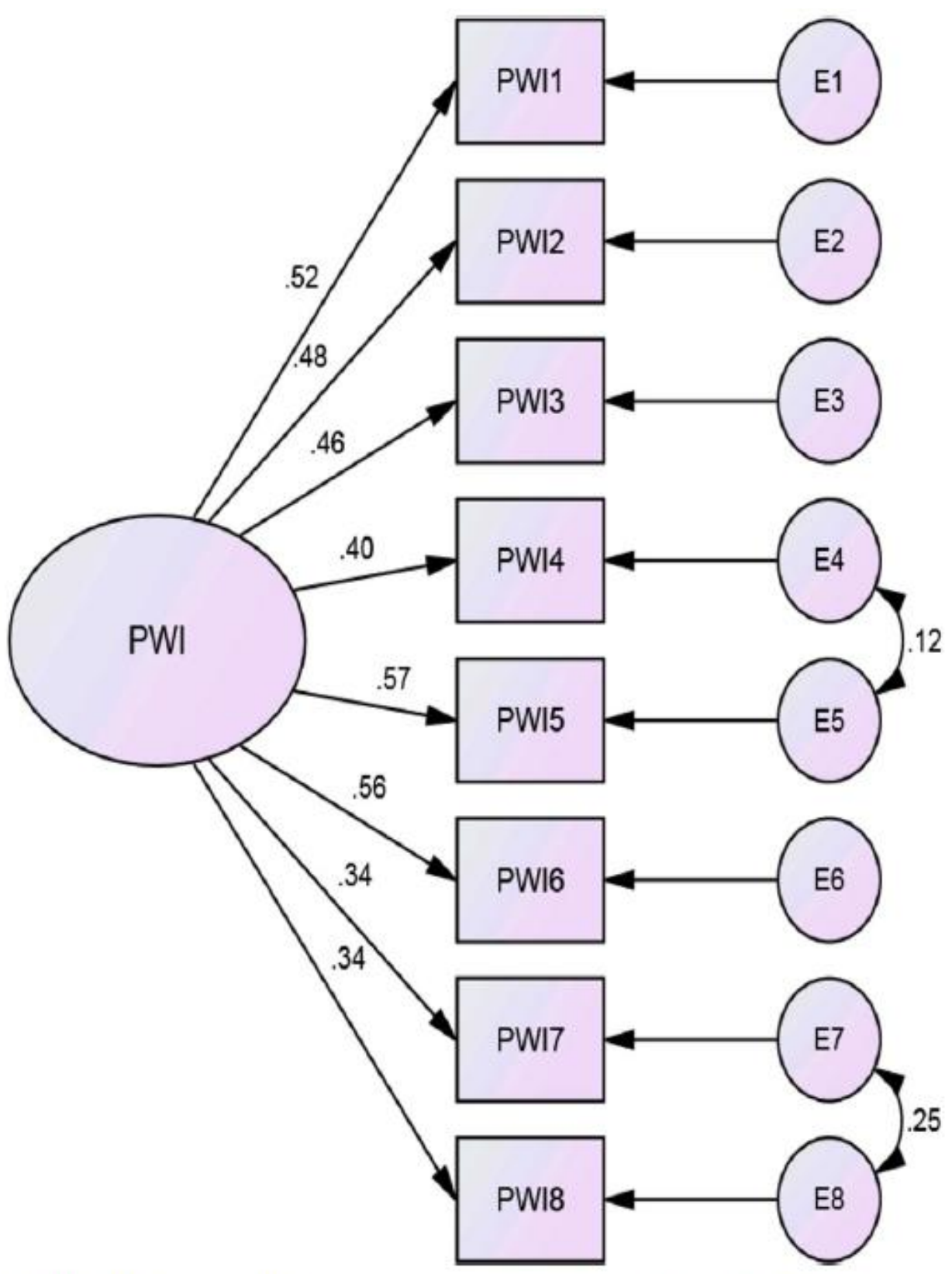

Fig. 3 PWI-SC (Modified Model with 2 error co-variances) using the pooled data

Appropriate fit statistics was found for the combined multi-group model. Metric and scalar factor invariance was tested by constraining the factor loadings and intercepts and was found to be tenable. Therefore, the overall multi-group model has a good fit structure and the two SES groups can be compared by correlations, regressions and means. An important finding of the study is that no significant mean differences were observed between the low and middle SES groups for both the SLSS and PWI-SC. This essentially indicates that children from the low and middle SES groups are presenting with similar levels of subjective well-being. 
Table 3 Confirmatory factor analysis (Standardised Regression Weights for items on the SLSS \& PWI-SC) using the pooled data

\begin{tabular}{lllllll}
\hline Bootstrap ML, 95 \% confidence intervals. Resamples = 500 & Estimate & Lower & Upper & Sig \\
\hline SLSS & & & & & & \\
Life going well & & SLSS & .747 & .697 & .802 & $<.05$ \\
Life just right & $\leftarrow$ & SLSS & .726 & .674 & .781 & $<.05$ \\
Have good life & $\leftarrow$ & SLSS & .786 & .737 & .837 & $<.05$ \\
Have what I want in life & $\leftarrow$ & SLSS & .637 & .578 & .689 & $<.05$ \\
Life better than most & $\leftarrow$ & SLSS & .507 & .448 & .573 & $<.05$ \\
PWI-SC & & & & & & \\
SatisfiedThingsHave & $\leftarrow$ & PWI-SC & .507 & .436 & .583 & $<.05$ \\
SatisfiedRelationships & $\leftarrow$ & PWI-SC & .382 & .302 & .462 & $<.05$ \\
SatisfiedSchoolExp & $\leftarrow$ & PWI-SC & .419 & .338 & .489 & $<.05$ \\
SatisfiedHealth & $\leftarrow$ & PWI-SC & .455 & .381 & .537 & $<.05$ \\
SatisfiedSafety & $\leftarrow$ & PWI-SC & .618 & .553 & .684 & $<.05$ \\
SatisfiedThingsGoodAt & $\leftarrow$ & PWI-SC & .546 & .474 & .609 & $<.05$ \\
SatisfiedAwayHome & $\leftarrow$ & PWI-SC & .315 & .243 & .378 & $<.05$ \\
SatisfiedLaterInLife & $\leftarrow$ & PWI-SC & .367 & .298 & .446 & $<.05$ \\
\hline
\end{tabular}




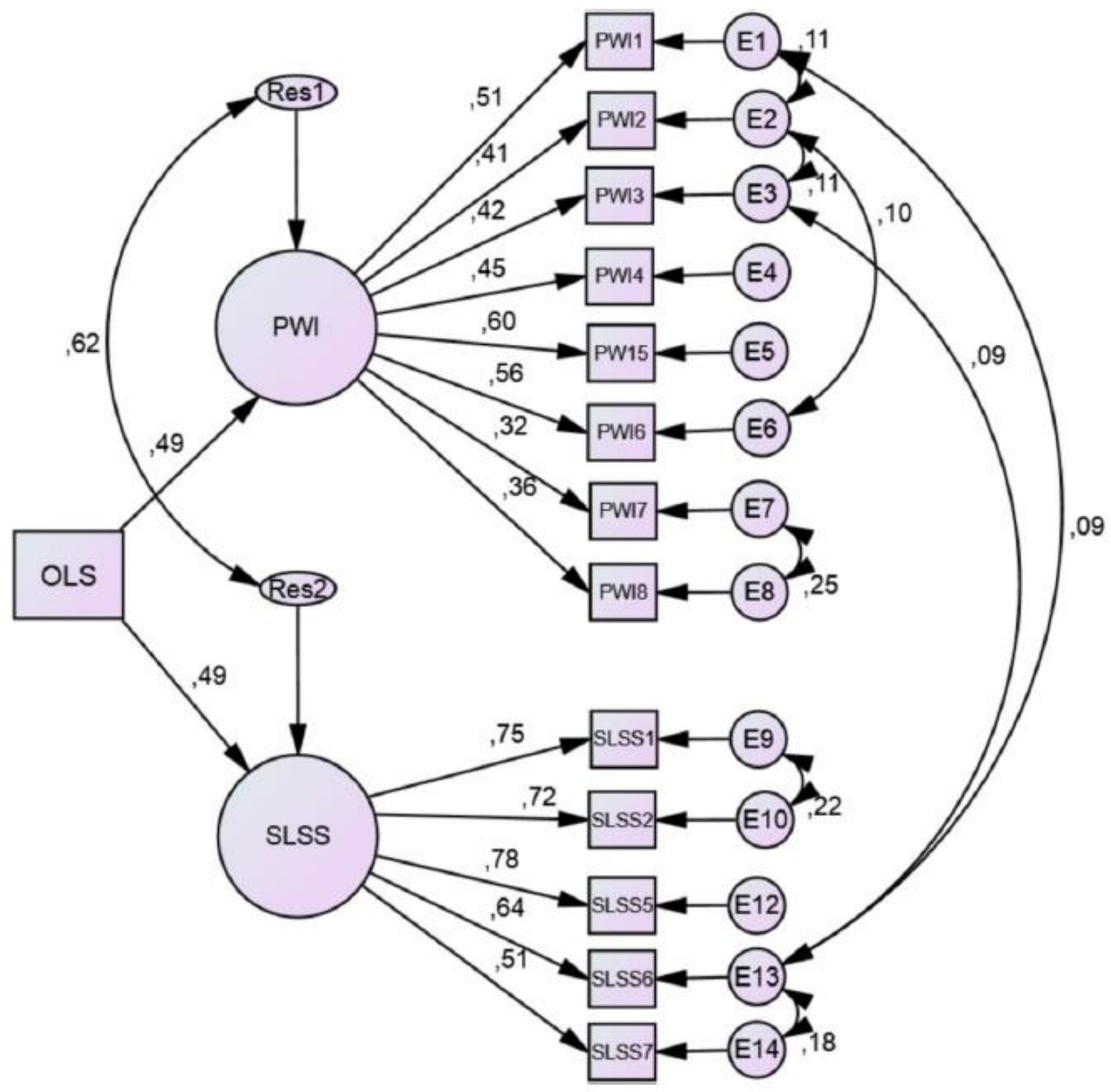

Fig. 4 SEM with 8 error co-variances including OLS using multi-group data 
Table 4 Standardised regression weights for items on the overall SEM (including OLS) across SES groups (constrained factor loadings and intercepts)

\begin{tabular}{|c|c|c|c|c|c|c|c|c|}
\hline \multirow{2}{*}{\multicolumn{3}{|c|}{$\begin{array}{l}\text { Bootstrap ML, } 95 \% \text { confidence intervals. } \\
\text { Resamples }=500\end{array}$}} & \multicolumn{3}{|c|}{ LOW SES } & \multicolumn{3}{|c|}{ MIDDLE SES } \\
\hline & & & \multirow{2}{*}{$\begin{array}{c}\text { Estimate } \\
.493\end{array}$} & \multirow{2}{*}{ Lower } & \multirow{2}{*}{ Upper } & \multirow{2}{*}{ Estimate } & \multirow{2}{*}{$\frac{\text { Lower }}{.375}$} & \multirow{2}{*}{$\frac{\text { Upper }}{.598}$} \\
\hline SLSS & $\leftarrow$ & OLS & & & & & & \\
\hline Life going well & $\leftarrow$ & SLSS & .758 & .699 & .815 & .774 & .688 & .800 \\
\hline Life just right & $\leftarrow$ & SLSS & .728 & .665 & .782 & .724 & .662 & .785 \\
\hline Have good life & $\leftarrow$ & SLSS & .801 & .749 & .843 & .751 & .672 & .826 \\
\hline Have what I want in life & $\leftarrow$ & SLSS & .655 & .592 & .708 & .603 & .529 & .679 \\
\hline Life better than most & $\leftarrow$ & SLSS & .521 & .449 & .598 & .478 & .409 & .554 \\
\hline $\begin{array}{l}\text { *SLSS Mean differences } \\
\text { between SES groups }\end{array}$ & & & 0 & 0 & 0 & $* *-.009$ & -.102 & -.102 .089 \\
\hline PWI-SC & $\leftarrow$ & OLS & .465 & .359 & .562 & .527 & .409 & .624 \\
\hline SatisfiedThingsHave & $\leftarrow$ & PWI-SC & .461 & .377 & .552 & .568 & .489 & .643 \\
\hline SatisfiedRelationships & $\leftarrow$ & PWI-SC & .362 & .297 & .435 & .533 & .433 & .647 \\
\hline SatisfiedSchoolExp & $\leftarrow$ & PWI-SC & .387 & .300 & .461 & .464 & .349 & .565 \\
\hline SatisfiedHealth & $\leftarrow$ & PWI-SC & .426 & .341 & .504 & .469 & .366 & .581 \\
\hline SatisfiedSafety & $\leftarrow$ & PWI-SC & .543 & .466 & .626 & .689 & .588 & .779 \\
\hline SatisfiedThingsGoodAt & $\leftarrow$ & PWI-SC & .517 & .449 & .589 & .634 & .543 & .723 \\
\hline SatisfiedAwayHome & $\leftarrow$ & PWI-SC & .290 & .232 & .347 & .441 & .343 & .531 \\
\hline SatisfiedLaterInLife & $\leftarrow$ & PWI-SC & .330 & .259 & .410 & .463 & .372 & .568 \\
\hline $\begin{array}{l}\text { *PWI-SC Mean differences } \\
\text { between SES groups }\end{array}$ & & & 0 & 0 & 0 & $* * .007$ & -.163 & .187 \\
\hline
\end{tabular}

*The low SES group is used as the point of reference

**Indicates non-significant mean differences

Convergent validity was tested by the inclusion of the observed variable OLS into the model with the two latent variables. Appropriate fit statistics were achieved for the overall pooled sample (SEM). The standardised regression weight of 0.49 for both the SLSS and PWI-SC suggest adequate loadings of the latent variables onto OLS. With a correlation of 0.62 between the two latent variables, the SLSS and PWI-SC are conceptually related yet distinct components of overall life satisfaction. Diener et al. (1999) have speculated that the various scales measuring subjective well-being and positive psychological constructs could possibly belong to the same higher order construct. Casas et al. (2012a, b), however, makes the important point that when first order factors are present, the first and second order models are equivalent and not testable against each other. In the final analysis, the overall SEM model showed good fit structure with metric and scalar factor invariance tenable - the overall model is valid for use in the Western Cape Province of South Africa, and low and middle SES groups can be compared by regressions, correlations and means. 


\section{Conclusion and Recommendations}

Measuring and monitoring initiatives of objective indicators have improved considerably in South Africa driven largely by the advancement of legislation aimed at improving the well-being of children. There is, however, a lack of data on subjective well-being, i.e. with regard to what children think and feel about their well-being and how they appraise different aspects of the daily life. Cross-cultural adaptation and translation of internation- ally validated instruments need to be advanced. While the current study has made a contribution in this regard, further translation and cross-cultural testing of other subjective well-being instruments are recommended. Furthermore, given the age variations of subjective well-being it is recommended that further research be conducted across various age groups. Finally, noting suggestions from Casas (2011) and Savahl et al. (2015c), qualitative research initiatives, which allow for a more in-depth understanding of children's subjective perceptions of well-being, are recommended.

\section{Acknowledgments}

The authors wish to thank the National Research Foundation of South Africa (project grant number: 87931) and the Jacobs Foundation for financial and institutional support. 


\section{References}

Bradley, R. H., \& Corwyn, R. F. (2002). Socioeconomic status and child development. Annual Review of Psychology, 53(1), 371-399.

Bradshaw, J., \& Richardson, D. (2009). An index of child well-being in Europe. Child Indicators Research, 2(3), 319-351.

Bradshaw, J., Keung, A., Rees, G., \& Goswami, H. (2011). Children's subjective well-being: international comparative perspectives. Children and Youth Services Review, 33, 548556.

Campbell, A., Converse, P. E., \& Rodgers, W. L. (1976). The quality of American life: Perceptions, evaluations and satisfaction. New York: Russell Sage.

Casas, F. (2011). Subjective social indicators and child and adolescent well-being. Child Indicators Research, 4(4), 555-575. doi:10.1007/s12187-010-9093-Z.

Casas, F., \& Rees, G. (2015). Measures of children's subjective well-being: analysis of the potential for cross-national comparisons. Child Indicators Research. doi:10.1007/s12187-014-9293-Z.

Casas, F., Sarriera, J. C., Alfaro, J., Gonzalez, M., Malo, S., Bertran, I., Figuer, C., Abs, D., Bedin, L., Paradiso, A., Weinreich, K., \& Valdenegro, B. (2012a). Testing the personal well-being index on 12-16 year-old adolescents in three different countries with two new items. Social Indicators Research. doi:10.1007/s11205-011-9781-1.

Casas, F., Sarriera, J. C., Abs, D., Coenders, G., Saforcada, J. A. E., \& Tonon, G. (2012b). Subjective indicators of personal well-being among adolescents. Performance and results for different scales in latin-language speaking countries: a contribution to the international debate. Child Indicators Research. doi:10.1007/s12187-011-9119-1.

Casas, Baltatescu, Bertran, Gonzalez, \& Hatos. (2013a). School satisfaction among adolescents: testing different indicators for its measurement and its relationship with overall life satisfaction and subjective well-being in Romania and Spain. Social Indicators Research. doi:10.1007/s11205-012-0025-9.

Casas, F., Bello, A., Gonzalez, M., \& Aligué, M. (2013b). Children's subjective well-being measured using a composite index: what impacts Spanish first-year secondary education students' subjective well-being? Child Indicators Research. doi:10.1007/s12187-013-9182-X.

Casas, F., Tiliouine, H., \& Figuer, C. (2013c). The subjective well-being of adolescents from two different cultures: applying three versions of the PWI in Algeria and Spain. Social Indicators Research. doi:10. 1007/s11205-012-0229-Z.

Cheung, G. W., \& Rensvold, R. B. (2002). Evaluating goodness-of-fit indexes for testing MI. Structural Equation Modelling, 9, 235-255.

Cummins, R. A. (1995). On the trail of the gold standard for subjective well-being. Social Indicators Research, 35, 179-200.

Cummins, R. A., \& Lau, A. D. L. (2005). Personal wellbeing index: School children (PWI-SC) (3rd ed.). Melbourne: Deakin University.

Diener, E. (2006). Guidelines for national indicators of subjective well-being and ill-being. Journal of Happiness Studies, 7, 397-404.

Diener, E. (2009). Culture and well-being. Dordrecht: Springer. 
Diener, E., Suh, E. M., Lucas, R. E., \& Smith, H. L. (1999). Subjective well-being: three decades of progress. Psychology Bulletin, 125(2), 276-302.

Diener, E., Lucas, R. E., \& Oishi, S. (2005). Subjective well-being: The science of happiness and life satisfaction. In C. R. Snyder \& S. J. Lopez (Eds.), Handbook of positive psychology (2nd ed., pp. 63- 73). New York: Oxford University Press.

Hall, K., Woolard, I., Lake, L., \& Smith, C. (Eds.). (2012). South African Child Gauge 2012. Cape Town: Children's Institute, University of Cape Town.

Hooper, D., Coughlan, J., \& Mullen, M. (2008). Structural equation modelling: guidelines for determining model fit. Electronic Journal of Business Research Methods, 6(1), 53-60.

$\mathrm{Hu}, \mathrm{L} .$, \& Bentler, P. M. (1999). Cutoff criteria for fit indexes in covariance structure analysis: conventional criteria versus new alternatives. Structural Equation Modeling A Multidisciplinary Journal, 6(1), 1-55.

Huebner, E. S. (1991). Initial development of the students' life satisfaction scale. School Psychology International, 12, 231-240.

Huebner, E. S., \& Alderman, G. L. (1993). Convergent and discriminant validation of a children's life satisfaction scale: its relationship to self- and teacher-reported psychological problems and school functioning. Social Indicators Research, 30, 7182.

Huebner, E.S. \& Hills, K.J. (2013). Assessment of subjective well-being in children and adolescents. In D.H. Saklofske, C.R. Reynolds \& V. Schwean (Eds.), The Oxford Handbook of Child Psychological Assessment, DOI 10.1093/oxfordhb/9780199796304.013.0034.

Huebner, E. S., Suldo, S. M., \& Valois, R. F. (2003). Psychometric properties of two brief measures of children's life satisfaction: the students' life satisfaction scale (SLSS) and the brief multidimensional students' life satisfaction scale (BMSLSS). Paper prepared for the Indicators of Positive Development Conference, March 12-13. Washington, DC: University of South Carolina.

Jaccard, J., \& Wan, C. K. (1995). Measurement error in the analysis of interaction effects between continuous predictors using multiple regression: multiple indicator and structural equation approaches. Psychological Bulletin, 117(2), 348-357.

Jackson, D. L., Gillaspy, J. A., Jr., \& Purc-Stephenson, R. (2009). Reporting practices in confirmatory factor analyses: AN overview and some recommendations. Psychological Methods, 14(1), 6-23.

Kline, R. B. (2010). Principles and practice of structural equation modelling (3rd ed.). New York: Guilford Press. Meredith, W. (1993). Measurement invariance, factor analysis, and factorial invariance. Psychometrika, 58, 525-542. Millsap, R. E., \& Olivera-Aguilar, M. (2012). Investigating measurement invariance using confirmatory factor analysis. In R. H. Hoyle (Ed.), Handbook of structural equation modeling (pp. 380-392). New York: Guilford.

Okulicz-Kozaryn, A. (2015). Income inequality and wellbeing. Applied Research in Quality of Life, 1O, 405-418. Ram, R. (2005). Income inequality, poverty, and population health: evidence from recent data for the United

States. Social Science \& Medicine, 61, 2568-2576. 
Ram, R. (2006). Further examination of the cross-country association between income inequality and population health. Social Science \& Medicine, 62, 779-791.

Rees, G., Pople, L., \& Goswami, H. (2011). Understanding children's well-being: Links between family economic factors and children's subjective well-being - initial findings from wave 2 and wave 3 quarterly surveys. London: The Children's Society.

Savahl, S., Adams, S., Isaacs, S., September, S., Hendricks, G., \& Noordien, Z. (2015a). Subjective well-being amongst a sample of South African children: a descriptive study. Child Indicators Research. doi:10.1007/ s12187-014-9289-8.

Savahl, S., Casas, F., \& Adams, S. (2015b). Validation of the children's hope scale amongst a sample of adolescents in the Western Cape Region of South Africa. Child Indicators Research. doi:10.1007/s12187-015-9334-2.

Savahl, S., Malcolm, C., Slembrouk, S., Adams, S., Willenberg, I. A., \& September, R. (2015c). Discourses on well-being. Child Indicators Research. doi:10.1007/s12187-014-9272-4.

Statistics South Africa. (2015). Mid-year population estimates. Pretoria: Stats SA.

Suldo, S. M., \& Huebner, E. S. (2004). Does life satisfaction moderate the effects of stressful life events on psychopathological behaviour during adolescence? School Psychology Quarterly, 19(2), 93-105.

Tomyn, A. J., \& Cummins, R. A. (2011). The subjective wellbeing of high-school students: validating the personal wellbeing index- school children. Social Indicators Research, $101,405-418$. 